\title{
Editorial
}

\section{Las causas socioambientales de la pandemia coviD-19}

Aunque ha sido corto el tiempo que ha pasado desde que la Organización Mundial de la Salud decretó, en marzo del presente año, el "estado de pandemia" [1], el volumen de documentación que se ha producido al respecto es impresionante y rebasa la capacidad que tiene cualquier persona, o aun cualquier grupo de estudio, para estar actualizado frente a lo que se publica. Esto hace particularmente difícil lograr un balance reposado ante el conocimiento adquirido acerca del comportamiento real de la epidemia en los diferentes entornos locales, sobre las especificidades del severe acute respiratory syndrome coronaviruses (SARS-CoV-2) como agente casual involucrado, acerca de la fisiopatología y las manifestaciones clínicas de la enfermedad y, por demás, en lo que se refiere a las causas de la aparición de tan atemorizante pandemia.

Pero aunque el panorama no sea del todo claro y aún existan demasiados aspectos ocultos cuyo esclarecimiento resulta esencial para comprender a cabalidad el fenómeno pandémico y así orientar de mejor manera las acciones preventivas y asistenciales, ya es posible tener una aproximación general a la complejidad de dicho fenómeno y establecer su vínculo con las dinámicas sociopolíticas, económicas y culturales de las sociedades contemporáneas.

Al revisar alguna de la documentación existente y analizar los hallazgos que tenemos a la mano, podemos decir, por lo pronto, que contamos con un conjunto de evidencias importantes que nos señalan que la pandemia actual no es un simple fenómeno natural que relaciona un virus con una especie biológica susceptible. Por supuesto que dicha relación está en la base del fenómeno pandémico, pero el asunto va más allá, toda vez que la pandemia se vincula, de manera íntima, con el tráfico de animales silvestres, el desarrollo de los monocultivos, la deforestación, la producción agroindustrial, el manejo fabril de las granjas, el abarrotamiento de los mercados de comida, el saqueo de la biodiversidad y, en últimas, la destrucción sistemática de los ecosistemas [2,3]. Por no hablar, claro está, de la hipermovilidad de los representantes comerciales de las empresas transnacionales, la rapidez de los sistemas de transporte, la masificación de las urbes y la enorme desigualdad social existente [4,5].

Esto nos conduce a una comprensión más amplia y profunda de la pandemia que exige, por demás, ahondar en el análisis de sus causas y consecuencias. En salud pública es común escuchar la expresión "la causa de las causas", para aludir tanto a la cadena causal que conduce a la ocurrencia de un fenómeno de interés como a los elementos de la estructura social que lo hacen posible. En últimas, es una manera de referirse a las causas estructurales de los fenómenos asociados a la salud y la enfermedad [6,7]. Ello ha permitido que se hable de manera amplia de los "determinantes sociales de la salud", pero también que se explore la relación entre ellos y se haga visible la necesidad de analizar los "procesos de determinación" que entran en juego [8].

Y es bajo esta última perspectiva que resulta esencial comprender que el modo como surge la pandemia tiene todo que ver con la forma en que, actualmente, nos relacionamos los seres humanos con las diferentes especies animales, y esto remite, de manera directa, a la industria de alimentos y a la explotación de los ecosistemas. Esto es así porque nos enfrentamos, en propiedad, a una zoonosis. Y, además, porque ya se hecho evidente la importancia que adquiere el llamado "mercado húmedo" de Wuhan, en la forma como el virus SARS-CoV-2 contagió al humano $[9,10]$.

Por tanto, hoy podemos afirmar que la presencia simultánea de alimentos exóticos y tradicionales en el mercado de Wuhan es posible por intrincadas redes comerciales que operan en una geografía económica que relaciona las urbes modernas, en plena expansión como Wuhan, con las zonas profundas de junglas y bosques, donde las diversas especies sufren hondas alteraciones y de donde se extraen exóticos patógenos que entran en contacto con otras especies animales alojadas en granjas y mercados. Como resultado, el virus SARS-CoV-2, alojado en murciélagos (o en otras especies, aún no se sabe todo al respecto), encuentra el camino para impactar de modo inclemente la vida social de los humanos [9]. Pero, a su vez, es el veloz intercambio comercial y la extraordinaria forma de movilidad aérea que tenemos los humanos, mediante una poderosa industria aeronáutica internacional, la que permite que el virus se disemine desde un pequeño mercado, en una de las provincias del emergente coloso económico llamado República China Popular, hasta los lugares más recónditos del planeta [5].

Como lo señala el biólogo evolutivo Rob Wallace, "La agricultura dirigida por el capital que reemplaza a las ecologías más naturales ofrece los medios exactos por los cuales los patógenos pueden evolucionar hacia los fenotipos más virulentos e infecciosos" [11]. Y por eso no es fortuito que otras epidemias como el sars hayan tenido como epicentro 
la misma zona geográfica. Pero, por supuesto, lo mismo puede ocurrir en otras regiones del planeta, como lo han demostrado las epidemias de gripe aviar de los años 2004-2005, de gripe porcina del 2009, del síndrome respiratorio de Oriente Medio (Middle East Respiratory Syndrome, MERs), en 2012-2014 y del Ébola, en 2014-2016.

Por eso se ha señalado, con cierta insistencia por parte de voces críticas, que las formas de producción actual aceleran la evolución de la virulencia de los patógenos y su posterior transmisión, dado que estimulan el uso de cultivo de monocultivos genéticos, colocan en situación de gran estrés inmunológico a los animales, facilitan la infección recurrente, proporcionan un suministro continuo de animales susceptibles y posibilitan que los virus salten la barrera interespecie $[3,11-15]$.

Entonces, las causas estructurales de la presencia de una desconocida y contagiosa partícula viral hoy llamada SARS-CoV-2, de la generalizada susceptibilidad poblacional, de la ausencia de inmunidad previa, de la carencia de vacunas y tratamientos, de la amenazante presencia de infectados asintomáticos y del caótico juego de las mutaciones genéticas están ancladas en las dinámicas de una sociedad voraz, cuyo modo de producción se basa en la explotación del ser humano, la dominación de los demás seres vivos y la destrucción de la naturaleza. Así podemos entender, en la actualidad, las causas socioambientales de la pandemia.

Juan Carlos Eslava C.

Profesor asociado

Departamento de Salud Pública

Facultad de Medicina

DOI: https://doi.org/10.17533/udea.rfnsp.e342049

Universidad Nacional de Colombia

\section{Referencias}

1. Organización Mundial de la Salud (OMS). Alocución de apertura del director general de la OMS en la rueda de prensa sobre la COVID-19 celebrada el 11 de marzo de 2020 [internet] 2020 [citado 2020 mar. 4]. Disponible en: https://www.who.int/es/dg/speeches/detail/who-directorgeneral-s-opening-remarks-at-the-media-briefing-on-covid-19---11-march-2020

2. Svanpa M. Reflexiones para un mundo post-coronavirus. Nueva Sociedad [internet]. 2020 [citado 2020 mar. 4]; (237). Disponible en: https:// www.nuso.org/articulo/reflexiones-para-un-mundo-post-coronavirus/

3. Wallace R, Liebman A, et al. El COVID-19 y los circuitos del capital. La Izquierda Diario. Semanario [internet]. 2020 mar. 29 [citado 2020 mar. 4]. Disponible en: https://www.laizquierdadiario.com/El-COVID-19-y-los-circuitos-del-capital\#nh29

4. Neiderud CJ. How urbanization affects the epidemiology of emerging infectious diseases. Infection Ecology and Epidemiology. 2015;5(1):27060. DOI: http://dx.doi.org/10.3402/iee.v5.27060

5. Ramonet I (2020). La pandemia y el sistema-mundo. La Jornada [internet]. 2020 may. 3 [citado 2020 mar. 4]. Disponible en: https://www. jornada.com.mx/ultimas/mundo/2020/04/25/ante-lo-desconocido-la-pandemia-y-el-sistema-mundo-7878.html

6. Braveman P, Gottlieb L. The social determinants of health: It's time to consider the causes of the causes. Public Health Rep. [internet]. 2014 [citado 2020 mar. 4]; 129(Suppl. 2):19-31. Disponible en: http://www.ncbi.nlm.nih.gov/pubmed/24385661

7. Marmot M. Inclusion health: Addressing the causes of the causes. Lancet. 2018;391(10117):186-8. DOI: https://doi.org/10.1016/S01406736(17)32848-9

8. Morales C, Borde E, et al. ¿Determinación social o determinantes sociales? Diferencias conceptuales e implicaciones praxiológicas. Rev Salud Pública [internet]. 2013 [citado 2020 mar. 4];15(6):797-804. http://www.scielo.org.co/pdf/rsap/v15n6/v15n6a03.pdf

9. Chuang. Contagio social: guerra de clases microbiológica en China. Viento del Sur [internet]. 2020 mar. 24 [citado 2020 abr. 4]. Disponible en: https://vientosur.info/spip.php?article15743

10. Leung K, Wu JT, et al. First-wave COVID-19 transmissibility and severity in China outside Hubei after control measures, and second-wave scenario planning: A modelling impact assessment. Lancet. 2020;395(10233):1382-93. DOI: https://doi.org/10.1016/S0140-6736(20)30746-7

11. Wallace R. Agronegocio capitalista y COVID-19: una combinación mortal. La Izquierda Diario [internet]. 2020 mar. 15 [citado 2020 abr. 4]. Disponible en: https://www.laizquierdadiario.com/Agronegocio-capitalista-y-Covid-19-una-combinacion-mortal

12. Atkins K, Read A, Sevill N, et al. Vaccination and reduced cohort duration can drive virulence evolution: Marek's disease virus and industrialized agriculture. Evolution. 2012;67(3):851-60. DOI: https://doi.org/10.1111/j.1558-5646.2012.01803.x

13. Houshmar M, Azhar K, Zulkifli I, et al. Effects of prebiotic, protein level, and stocking density on performance, immunity, and stress indicators of broilers. Poult Sci. 2012;91(2): 393-401. DOI: https://doi.org/10.3382/ps.2010-01050

14. Pitzer V, Aguas R, Riley S, et al. High turnover drives prolonged persistence of influenza in managed pig herds. J R Soc Interface. 2016;13(119):20160138. DOI: https://doi.org/10.1098/rsif.2016.0138

15. Wallace R. Big Farms make Big Flu. Dispatches on Infectious Disease, Agribusiness, and the Nature of Science. New York: Monthly Review Press; 2016. 